\title{
A Systematic Review on Mathematical Language Learning Using PRISMA in Scopus Database
}

\author{
Rosmawati Mohamed ${ }^{1 *}$, Munirah Ghazali ${ }^{1}$, Mohd Ali Samsudin ${ }^{1}$ \\ ${ }^{1}$ School of Educational Studies, Universiti Sains Malaysia, Penang, MALAYSIA
}

Received 1 April 2020 - Accepted 16 May 2020

\begin{abstract}
Through a search executed on Scopus database with general keywords such as 'mathematical language' and related terms, this study reveals the analysis of previous published articles based on PRISMA's procedure where it guides researchers' self-regulated learning on online platform. This review exhibits both inclusion and exclusion criteria in the publication distribution. Whilst, all included documents are articles in English language; the excluded articles are those from medicine subject area. The distribution of articles published specifically by years, subject areas, authors, countries and authors' affiliated universities were examined. The varied of findings show Scopus database provides essential information pertaining to mathematical language and approach carried out involving students from various level. The study also reveals there are wide-ranging articles related to mathematical language and technology approach in the database. Meanwhile, developing student's mathematical language learning using technology is one of the effective strategies. However, less attention has been given to such approach.
\end{abstract}

Keywords: mathematical language, PRISMA, Scopus, student, review

\section{INTRODUCTION}

\section{Mathematical Language}

Previous study revealed that there are at least three main sources of students' challenges using mathematical language which include mathematical language, image and notation (Alkhateeb, 2019), getting started on a proof, and conceptual understanding (Moore, 1994). First, the challenges with mathematical language are discussed in terms of mathematics register involving new meanings for everyday words (e.g. column, odd, prove), new words with specific meanings (e.g. hypotenuse), and modes of argument (Zack, 1999). For example, many children have limited understanding of 'more' and 'less' (Warren, 2006) and logical connectives such as 'because', 'but', and 'if...then' which are linked to generalizations to make arguments of mathematically strong (Zack, 1999).

Second, the challenges with proof understanding from Exist-All (EA) and All-Exist (AE) statements are presented. EA statements such as "There exists ... for all ..." convey various interpretations than $\mathrm{AE}$ statement such as "For all . . . there exists...". It was found that students' proof skills for such statements modified their understanding of these statements. Moreover, confronted statement with EA and/or AE forms could help them determine the appropriate mathematical meanings. Therefore, the use of formal logic and knowledge of mathematical language structure are useful tools in proving mathematical statements (PiatekJimenez, 2010).

Third, the challenges with conceptual understanding could be interpreted via self-explaining process. The process commences as the students' attempt to describe targeted mathematical concepts regardless of the language type used, either formal or informal terms to explain reasoning. Besides, individual language abilities influence mathematics word problem solving achievement for most students at various levels (Walkington, Clinton, \& Sparks, 2019).

Students who frequently practice using formal language would have greater procedural knowledge gains (McGinn \& Booth, 2018). However, by evaluating only the procedural 'doing' of mathematics, it cannot be completely achieved without mathematical vocabulary 


\section{Contribution to the literature}

- This study demonstrates a step by step of PRISMA searching procedures (e.g., identification, screening, eligibility and inclusion) to enhance students' self-regulated learning through online platform.

- This study offers various educational level, methods and tools on the mathematical language usage among students employed in recent articles that may help teacher to identify strategies for teaching mathematics.

- This study identifies online learning environments as an important approach which engages students with mathematical language and transforms informal mathematical language to more formal one.

(and language) (Van Jaarsveld, 2018). Vocabulary was found to be a significant predictor for executive functioning $(\mathrm{EF})$ which is defined as a process that controls thought and action; whereby mathematical language is related to the development of EF. Language complexity such as abstract vocabulary must be considered in exploring the factors contribute to EF development in the early years (Schmitt, Purpura, \& Elicker, 2019).

Therefore, increasing children's exposure to mathematical language can positively affect their general mathematics skills (Purpura, Napoli, Wehrspann, \& Gold, 2016), spatial mathematical skills (Medina Herrera, Castro Pérez, \& Juárez Ordóñez, 2019) and numeracy skills (Hornburg, Schmitt, \& Purpura, 2018). General mathematics skills refer to mathematical language that is highly content specific; whereby the use of this specific language affects children's mathematical knowledge (Purpura et al., 2016). Spatial mathematical skills are related to the utterance of spatial relations of which movement between objects is among significant considerations (Rudd, Lambert, Satterwhite, \& Zaier, 2008). Important skill at the initial mathematical language utilization is numeracy skills. Understanding numerical skills involves number sense such as verbal counting, numeral identification, ordering numerals, comparisons of sets and/or numerals, cardinality, story problems and one to-one correspondence (Hornburg et al., 2018).

Previous studies indicate several different definitions for mathematical language. Generally, mathematical language or language of mathematics is defined as vocabulary, word order, syntax, and abbreviations unique to mathematics (Simpson \& Cole, 2014). Definition from Bakhtin (1981) ideas more than just teaching vocabulary; mathematical language is understood through classroom interaction whereby situated dialogic relations exist between multiple discourses, voices and languages (Barwell, 2015). Therefore, interactions or communications emerged involve the use of mathematical language.

Many scholars define mathematical language in terms of utilization of mathematical language. Using mathematical language means understanding the language about one's own learning ( $\mathrm{O}^{\prime}$ Brian, Nocon, \& Sands, 2010). Specifically, the use of language comprises using correct or exact formal mathematics terminology (McGinn \& Booth, 2018; Van Jaarsveld, 2016). Those include using mathematical language and notation in doing proof and using mathematical statements (Moore, 1994; Piatek-Jimenez, 2010). Thus, employing formal language regularly leads to higher procedural knowledge acquisition (Simpson \& Cole, 2014).

The use of mathematical language involves the interpretation of mathematical meaning (Warren, 2006) through students' reflection on their classroom assessment performance and their explanation on the ways they attain correct and incorrect answers; then setting specific goals to improve their learning in future (O'Brian, Nocon, \& Sands, 2010). Interpretation on symbolic mathematical language is also used in formal language of other fields such as physics (De Lozano \& Cardenas, 2002) and computer systems (Zinn, 2006).

The interpretation of meaning does not merely depend on knowledge of key words or concepts (Hornburg et al., 2018), but also relies on understanding the key words used in mathematics (Purpura et al., 2016). Understanding the keywords refers to students' capability of using appropriate mathematical vocabulary (Barwell, 2015; Caniglia, Borgerding, \& Meadows, 2017; Firmender, Gavin, \& McCoach, 2014) including the ability to discriminate mathematical vocabulary usage to promote academic outcomes (Van Jaarsveld, 2016). This can be known through students' spoken words that transform from everyday language to more formal mathematical language (Simpson \& Cole, 2014). The connection between informal and formal mathematical languages represents the beauty of word pattern (Serder \& Jakobsson, 2015). Therefore, from previous definitions, mathematical language can be defined as specific focus on vocabulary to help students in connecting informal and formal mathematical languages using linguistic and communicative resources to obtain information (Caniglia et al., 2017).

Test, tasks, assessments, courses, project and assignments are various typical resources used in previous studies to examine student's mathematical language development (Hornburg et al., 2018; Moore, 1994; Piatek-Jimenez, 2010; Schmitt et al., 2019; Van Jaarsveld, 2016; Zack, 1999). However, different fields can benefit from the utilization of various technology tools and internet software which transforms 
conventional learning into more interactive and engaging environment in the classroom. In language area, online tools such as Barrier game or Desmos ${ }^{\prime}$ Polygraph program are developed for transforming informal language into formal language. Such online tools facilitate students' construction of mathematical knowledge through learning and application process to be more authentic (Caniglia et al., 2017). Additionally, language games are also used in small groups for science intervention (Serder \& Jakobsson, 2015). In mathematics education, virtual environments such as 3D tools and 3D printing are adapted in developing spatial mathematical skills in higher education (Medina Herrera et al., 2019). Meanwhile in lower and middle grades; online problemsolving environment is utilized to examine the effects of individual language features on word problem solving performance (Simpson \& Cole, 2014). Therefore, there are three main dimensions for the mathematical language learning, namely knowledge of the meaning of mathematical words, application of discourse, reading and writing of mathematical language in the classroom and ability to understand word problems (Warren, 2016).

The purpose of this study is to review previous published articles on mathematical language learning. This study will help researchers in obtaining information about the experts in mathematical language including country of origin and affiliation, subject areas and the focus of recent research on mathematical language studies. From educators' perspectives, this review may assist in improving their understanding on how mathematics is used specifically to discover deficiencies that require modification or supplementary materials in the classroom.

Furthermore, the information gathered from content analysis review enables them to evaluate their own teaching methods, use appropriate mathematical language in their learning, associate and develop new ideas into their own study and implement desired instructional processes. This analysis will also benefit policy makers, textbook's writers, education leaders, researchers and teachers to the extent of which researches to date on mathematical language are analysed and clarified. The results can help allocating existing materials and resources needed and making organization to guide future research.

\section{PRISMA}

Preferred Reporting Items for Systematic reviews and Meta-Analyses (PRISMA) statement was developed in 2005 and was regularly reported by David Moher and the team in their published medical article (Moher et al., 2009). PRISMA statement consist of four steps, namely, identification, screening, eligibility and inclusion criteria. Identification is the process to enrich main keywords using several steps so that articles from the database could be retrieved as wider as possible. The second phase is screening, a process to include or exclude articles base on criteria decided by authors and generated using database. Exclude articles means to remove unnecessary articles according to the types of articles. The third phase is eligibility, all articles were examined by reading through the title, abstract, method, result and discussion to ensure they meet the inclusion criteria and parallel with the current research objectives. The final phase, inclusion criteria where the articles left and fulfil the requirement to be analysed.

PRISMA can also be used as the foundation for reporting systematic review and benefits various fields (Moher et al., 2009). At least three major benefits of using PRISMA as guidance procedure in online training environment specifically for students, teachers, researchers or other readers. First, PRISMA procedure provides systematic searching procedures (e.g., identification, screening, eligibility and inclusion) to enhance students' self-regulated learning through online platform. Second, a step-by step procedure may be used by post graduate students or researchers as useful guidance to support their comprehensive searching to attain the required articles. Third, the PISMA procedures provide readers with clear comprehension of the process, easy observation of the connection between information and its sources via systematic reviews recording and straightforward evaluation of reported systematic reviews.

Based on the discussion of PRISMA procedure presented, explicit aspects of mathematical language learning are better supported. However, limited reviews on mathematical language learning researches in Scopus database utilizing PRISMA procedure as the guideline for documents search were discovered, not to mention reviews on content analysis. For example, content analysis reviews by Voronina, Tretyakova, Krivonozhkina, Buslaev, and Sidorenko (2019), Aydin (2019), Genç, Masalimova, Platonova, Sizova, and Popova (2019), Odabasi, Uzunboylu, Popova, Kosarenko, and Ishmuradova (2019), Ozcinar, Zakirova, Kurbanov, and BelyalovaSimpson and Cole (2019) and Zack (1999) in Scopus database definitely do not apply PRISMA procedure. Therefore, extensive content analysis is needed to better understand the researches conducted on knowledge and understanding of mathematical language and how to apply them. This study utilizes PRISMA procedure to guide self-regulated learning on online platform.

\section{The Objectives of the Study}

The purpose of this study is to examine the researches on mathematical language learning using PRISMA in Scopus database. Under this general aim, the answers are searched for the following research questions (RQ):

RQ1: How are the articles distributed over the years? 
Table 1 . The search string

\begin{tabular}{ll}
\hline Database & Search String \\
\hline Scopus & TITLE-ABS-KEY ( ( "mathematical language" ) AND ( "children" OR "students" OR "pupils" $)$ AND ( "everyday" \\
& OR “informal" OR “spoken" OR “formal" OR "vocabulary" OR "quantitative" OR "spatial" $)$ )
\end{tabular}

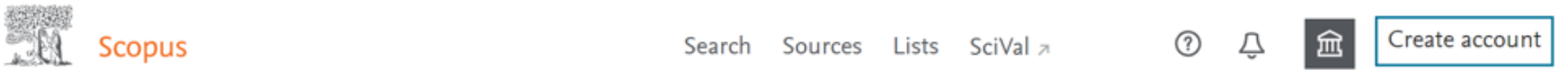

\section{Advanced search compare sources >}

Documents Authors $\bigcirc$ Affiliations
Enter query string
TITLE-ABS-KEY (( "mathematical language"
("everyday" AND ( "children" OR "informal" OR "spoken" OR "formal" OR "vocabulary" OR "quantitative" OR
"spatial"))

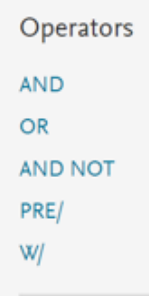

Figure 1. Advanced menu to enter search string

RQ2: What is the distribution of subject areas in the articles?

RQ3: What is the distribution of authors in the articles?

RQ4: What is the distribution of authors' country of origin in the articles?

RQ5: What is the distribution of authors' affiliation in the articles?

RQ6: What is the distribution of 'what', 'who' and 'how' associated with mathematical language and learning approach in the articles?

\section{METHODOLOGY}

\section{The PRISMA Procedure}

Titles and abstracts of 27 articles were filtered by the first author after inclusion and exclusion process which was automatically completed using database system (Table 2); and 25 articles were selected to be read in full text. The first author read full text of all articles. Whilst, the second author read full text of fifteen articles; the third author read subsequent ten articles. These three authors discussed the articles' relevancy to the study's research questions; then determined if it meets the inclusion criteria. When there was any doubt as to whether the article met the inclusion criteria, the second author conducted an independent evaluation. Finally, twenty articles were included. The selection process is shown in Figure 4.

\section{Scopus Database Resource}

The present study utilized the most common database that is Scopus. Scopus has its own uniqueness as it is produced by reputable Elsevier Co and indexed over 14000 journals for numerous fields including social sciences and mathematics.

\section{Limitations of Study}

This research is limited to the selected articles in Scopus database, accessed via Universiti Sains Malaysia database, one of Malaysia public universities. Content analysis of the articles is limited to six themes specified in RQ1 to RQ6; whereby themes in RQ6 is limited to three categories. In addition, using single database exclusively has its shortcomings since it does not cover all languages, all fields and all journals in the world (Falagas, Pitsouni, Malietzis, \& Pappas, 2008). Hence, this study only utilized this database to provide systematic and complete article searching procedure and analysis.

\section{The Systematic Review Processes}

\section{Identification}

The first process involves the identification process whereby main keywords are enriched by identifying, searching and listing its synonyms so that articles from the database could be retrieved as many as possible. The researchers began to gererate search strings using Scopus formatting in February 2020 (Table 1) through Universiti Sains Malaysia database.

Next, the search string was pasted on Enter query string in Advanced menu (Figure 1). As a result 49 documents were retrieved at the first phase (Figure 2).

\section{Screening}

The second phase is called the screening process whereby articles are included or excluded based on the criteria decided by the researchers and generated using 


\section{9 document results}

TITLE-ABS-KEY (( "mathematical language") AND ("children" OR "students" OR "pupils") AND ("everyday" OR "informal" OR "spoken" OR "formal" OR "vocabulary" OR "quantitative" OR "spatial"))

Figure 2. The number of documents accessed on Scopus database using search string

Table 2. The included and excluded criteria

\begin{tabular}{|c|c|c|}
\hline Criteria & Inclusion & Exclusion \\
\hline Type of ar & $\begin{array}{l}\text { Journal (research } \\
\text { articles) }\end{array}$ & conference proceeding, systematic review articles, book series, chapter in book and books \\
\hline Language & English & Non-English \\
\hline Timeline & until February 2020 & - \\
\hline Field & Other than medicine & Medicine \\
\hline
\end{tabular}

\begin{tabular}{lc} 
Language & $\wedge$ \\
$\square$ English & $(45)>$ \\
$\square$ Turkish & $(2)>$ \\
$\square$ German & $(1)>$ \\
$\square$ Russian & $(1)>$ \\
& \\
\hline Limit to Exclude &
\end{tabular}

\begin{tabular}{|c|c|c|c|c|}
\hline . & $\begin{array}{l}\text { teaching mathematical language games of different forms of life } \\
\text { ([] Book Chapter) }\end{array}$ & Wanderer, $F$. & $\cdots$ & $\begin{array}{l}\text { Social Practice: } \\
\text { Global and } \\
\text { Local } \\
\text { Perspectives } \\
\text { pp. 121-132 }\end{array}$ \\
\hline & View abstract $\checkmark$ (C) Linksource View at Publisher Related doc & uments & & \\
\hline & $\begin{array}{l}\text { Understanding how multilingual students translate word } \\
\text { problems to linear algebraic representations: An error analysis }\end{array}$ & $\begin{array}{l}\text { Madzorera, A., } \\
\text { Essien, A.A. }\end{array}$ & 2018 & $\begin{array}{l}\text { International } \\
\text { Journal of } \\
\text { Interdisciplinary }\end{array}$ \\
\hline
\end{tabular}

Figure 3. The procedure to include and exclude the access documents

database. Whilst, the term 'included articles' refers to the articles that meet the required criteria; the 'excluded articles' refers to the unnecessary articles that are removed according to its' types. The included and excluded criteria are summarised in Table 2.

The researchers continued the process by selecting the types of document in the database for 'article' and those that are in 'English Language'. The procedure to include the types was carried out by clicking on left side box of the website interface and chose the Limit to button at the bottom of the tick boxes. Then, subject area of Medicine was excluded by pressing Exclude button at the bottom of the tick boxes (Figure 3). Consequently, the screening process produced 27 articles. Later, the researchers examined the distribution of articles published specifically by years, subject areas, authors, countries and authors' affiliated universities. Out of 27 articles, two articles were excluded as the researchers failed to obtain full-text articles. Furthermore, the abstracts lack information required especially full result and whole picture of the topic.

\section{Eligibility}

Therefore, 25 articles were included in the third phase known as the eligibility process. All articles were examined by reading through the titles, abstract, method, result and discussion to ensure they met the inclusion criteria and parallel with current research objectives. It was discovered that five articles needed to be rejected based on two criteria; one is they did not involve students and two is type of the article. Finally, only 20 articles left and fulfilled the requirements to be analyzed (Figure 4).

\section{RESULTS}

Two steps were carried out to examine the articles and obtain the data for the study. Firstly, the researchers investigated PRISMA's Screening phase (Figure 4); whereby 27 articles were obtained as filtering process automatically took place using Scopus database. It is important to note that a total of 5 categories: years, subject areas, authors, authors' country of origin and authors affiliation, were examined to answer the first to the fifth sub-objective. Secondly, the researchers investigated PRISMA's Included phase (Figure 4); whereby 20 articles were selected via researchers' manual filtering process and 3 categories: 'what', 'who' and 'how', were examined to answer the sixth subobjective. 


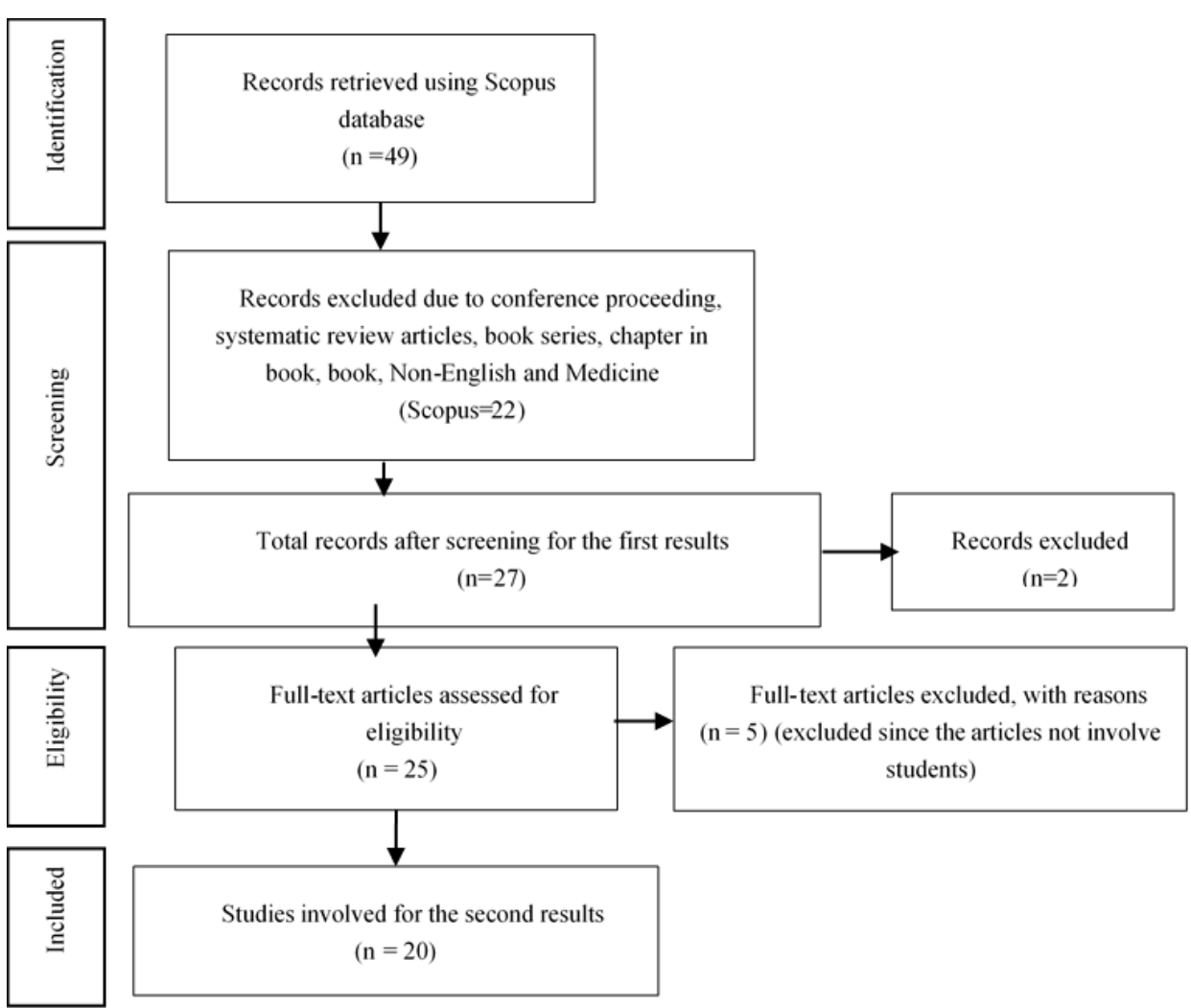

Figure 4. PRISMA's flow map

Table 3. Distribution of articles by years

\begin{tabular}{ll}
\hline Years & F \\
\hline 2019 & 3 \\
2018 & 4 \\
2017 & 2 \\
2016 & 4 \\
2015 & 1 \\
2014 & 1 \\
2012 & 2 \\
2010 & 2 \\
2008 & 1 \\
2007 & 1 \\
2006 & 2 \\
2002 & 1 \\
1999 & 1 \\
1994 & 1 \\
1991 & 1 \\
\hline
\end{tabular}

\section{RQ1: How are the Articles Distributed over the Years?}

A shown in article distribution according to its publication year in Table 3, no article publication is available in one group of two consecutive year in 1992 and 1993, two groups of three consecutive year in 2011, 2012, 2013 and 2003, 2004, 2005. It was also noticed that there is no article published for one group in four consecutive year between 1995 to 1998; and the biggest gap is for one group in five consecutive year from 2001to 2005. Therefore, there were not many article publications in mathematical language from 1991 to 2014; of which total number of article publications available within these 24 years period is only 13 articles. However, article
Table 4. Distribution of articles by subject areas

\begin{tabular}{lc}
\hline Subject area & $\mathrm{f}$ \\
\hline Social Sciences & 23 \\
Mathematics & 10 \\
Psychology & 6 \\
Engineering & 3 \\
Arts and Humanities & 2 \\
Computer Science & 1 \\
Physics and Astronomy & 1 \\
\hline
\end{tabular}

publication increases gradually within the last five years from 2014 to 2019 of which 14 articles were published. It shows that current researchers are getting more interested to study the field of mathematical language.

\section{RQ2: What is the Distribution of Subject Areas in the Articles?}

Within the scope of current research from Scopus database, number of scientific articles executed in different research fields investigated and its results are presented in Table 4. The distribution of subject areas in the articles shows that most studies were conducted in Social Sciences with 23 articles; followed by Mathematics with 10 articles. However, publication frequency related to mathematical language is extremely lacking in two areas: Computer Science and Physics and Astronomy. It shows that scholars from Social Sciences and Mathematics are those who were interested in mathematical language studies. It also reveals that researchers from Computer Science area were also 
Table 5. Distribution of articles by authors

\begin{tabular}{lllllll}
\hline Authors & f & Authors & f & Authors & f & Authors \\
\hline Purpura, D.J. & 3 & Elicker, J.G. & 1 & Madzorera, A. & 1 & Sands, D.I. \\
Schmitt, S.A. & 2 & Essien, A. A. & 1 & McCoach, D.B. & 1 & Sanger, M. \\
Van Jaarsveld, P. & 2 & Firmender, J.M. & 1 & McGinn, K.M. & 1 & Satterwhite, M. \\
Arcavi, A. & 1 & Gavin, M.K. & 1 & McLeman, L. & 1 & Serder, M. \\
Barwell, R & 1 & Giddings, M.M. & 1 & Meadows, M. & 1 & Simpson, A. \\
Booth, J.L. & 1 & Gold, Z.S. & 1 & Medina Herrera, L. & 1 & Sparks, A. \\
Borgerding, L. & 1 & Hadas, N. & 1 & Moore, R.C. & 1 & Walkington, C. \\
Caniglia, J. & 1 & Hornburg, C.B. & 1 & Napoli, A. R. & 1 & Warren, E. \\
Cardenas, M & 1 & Jaafar, R. & 1 & Nocon, H. & 1 & Wehrspann, E.A. \\
Castro Perez, J. & 1 & Jakobsson, A. & 1 & O'Brian, J.R.O. & 1 & Zack, V. \\
Clinton, V. & 1 & Juarez Ordonez, S. & 1 & Piatek-Jimenez, K. & 1 & Zaier, A. \\
Cole, M.W. & 1 & Karsenty, R. & 1 & Pirie, S. & 1 & Zinn, C \\
De Lozano, S.R. & 1 & Lambert, M.C. & 1 & Rudd, L.C. & 1 & 1 \\
\hline
\end{tabular}

Table 6. Distribution of articles by authors' country of origin

\begin{tabular}{lc}
\hline Countries/ Area & $\mathrm{f}$ \\
\hline United States & 15 \\
South Africa & 3 \\
Canada & 2 \\
United Kingdom & 2 \\
Argentina & 1 \\
Australia & 1 \\
Israel & 1 \\
Mexico & 1 \\
Sweden & 1 \\
\hline
\end{tabular}

interested in studies related to mathematical language as presented in Table 4.

\section{RQ3: What is the Distribution of Authors in the Articles?}

Table 5 indicates that 51 authors have significant works published in mathematical language. Out of 51, Purpura has three publications; meanwhile, Schmitt, Van Jaarsveld and Wehrspann have two publications each. The trend for the other authors remains constant with one publication each. Thus, it can be observed that prominent scholar in mathematical language is Purpura with the highest number of articles published; followed by Schmitt, Van Jaarsveld and Wehrspann.

\section{RQ4: What is the Distribution of Authors' Country of Origin in the Articles?}

Top nine countries published the most mathematical language related articles in Scopus database is presented in Table 6. The results illustrate that the United States has the most scientific works executed and published in mathematical language with 15 articles. This value is far different compared to South Africa at the second rank with only three article publications. Meanwhile, Canada and United Kingdom are at the third rank with two article publications each. Five other countries such as Argentina, Australia, Israel, Mexico and Sweeden have the least article published one article each. Hence, it is evidence that western countries produce the highest number of article publications in mathematical
Table 7. Distribution of articles by authors' affiliation

\begin{tabular}{|c|c|c|c|}
\hline Affiliation & $\mathrm{f}$ & Affiliation & $\mathrm{f}$ \\
\hline Purdue University & 3 & $\begin{array}{l}\text { Southern Methodist } \\
\text { University }\end{array}$ & 1 \\
\hline $\begin{array}{l}\text { University of } \\
\text { Witwatersrand }\end{array}$ & 3 & $\begin{array}{l}\text { Weizmann Institute of } \\
\text { Science Israel }\end{array}$ & 1 \\
\hline Tiffin University & 1 & $\begin{array}{l}\text { Texas Tech University at } \\
\text { Lubbock }\end{array}$ & 1 \\
\hline $\begin{array}{l}\text { St. George's Elementary } \\
\text { School }\end{array}$ & 1 & $\begin{array}{l}\text { University of Michigan- } \\
\text { Flint }\end{array}$ & 1 \\
\hline $\begin{array}{l}\text { Southern College of } \\
\text { Seventh-Day Adventists }\end{array}$ & 1 & University of Connecticut & 1 \\
\hline Valdosta State University & 1 & University of Dakota & 1 \\
\hline $\begin{array}{l}\text { Saint Joseph's University, } \\
\text { United States }\end{array}$ & 1 & Clemson University & 1 \\
\hline $\begin{array}{l}\text { City University of New } \\
\text { York }\end{array}$ & 1 & University of Oxford & 1 \\
\hline Malmo Hogskola & 1 & University of Edinburgh & 1 \\
\hline $\begin{array}{l}\text { Technologico de } \\
\text { Monterrey }\end{array}$ & 1 & $\begin{array}{l}\text { University of Ottawa, } \\
\text { Canada }\end{array}$ & 1 \\
\hline $\begin{array}{l}\text { Central Michigan } \\
\text { University }\end{array}$ & 1 & Kent State University & 1 \\
\hline $\begin{array}{l}\text { University of Colorado at } \\
\text { Denver }\end{array}$ & 1 & Temple University & 1 \\
\hline $\begin{array}{l}\text { Australian Catholic } \\
\text { University }\end{array}$ & 1 & $\begin{array}{l}\text { College of Health and } \\
\text { Human Sciences }\end{array}$ & 1 \\
\hline
\end{tabular}

language. This proves that western researchers paid serious attention on mathematical language issues.

\section{RQ5: What is the Distribution of Authors' Affiliation in the Articles?}

Table 7 shows the distribution of authors' affiliation pertaining to mathematical language article publications. Out of 26 institutions, two with the most number of article publications are Purdue University and University of Witwatersrand with three publications each. The publication frequency remains constant for 24 other institutions with one article publication each. 
Table 8. Distribution of 'what', 'who' and 'how'

\begin{tabular}{|c|c|c|c|}
\hline Authors & Year What tools/ approach? & Who involve? & How? \\
\hline $\begin{array}{l}\text { Medina Herrera, J. Castro Pérez } \\
\text { and S. Juárez Ordóñez (2019) }\end{array}$ & 2019 virtual environments, team working & $\begin{array}{c}\text { University } \\
\text { students }\end{array}$ & Test \\
\hline
\end{tabular}

C. Warkington, 2019 online problem-solving environment

Preschool childrer

S.A. Schmitt, D.J. Purpura, and 2019 Vocabulary task, Mathematical language assessment, Executive

J.G. Elicker (2019) Functioning (EF) task, behavioral assessment, children's inhibitory

Preschool children Assessments control task and early mathematics skills task.

B.C. Hornburg, S.A. Schmitt, and 2018 Mathematical language and specific numeracy skills (e.g., $\quad$ Preschool children Assessments

D.J. Purpura (2018) cardinality, numeral comparison).

P. Van Jaarsveld (2018) 2018 Students were required to write, in language suitable for teaching, a Trainee teacher Writing task description of the procedure which led to a solution. On-line methods were used to obtain data

K.N. McGinn, and J.L. Booth 2018 Self-explanation prompts (questions) and students' self-explaining Secondary school Assignments (2018)

D.J. Purpura, A. R. Napoli, E.A. 2016 Course of eight weeks, interventionists implemented a dialogic Preschool children Assessment Wehrspann, and Z. S. Gold (2016)

J. Caniglia, L. Borgerding, and

M. Meadows (2017)

R. Barwell (2015) reading intervention focused on quantitative and spatial mathematical language.

\begin{tabular}{lrc} 
& interaction. & discussion \\
\hline $\begin{array}{l}\text { M. Serder, and A. Jakobsson } \\
(2016)\end{array}$ & $\begin{array}{l}\text { Language games in the small groups of students discussed and } \\
\text { collaboratively solved Programme for International Student }\end{array}$ & $\begin{array}{c}\text { Secondary school } \\
\text { students }\end{array}$
\end{tabular}
(2016) Assessment (PISA) science test items.

R. Jaafar (2016)

2016 Several writing-to-learn activities (WTL) assignments with checklist College students Assignments (prompt questions), classroom discussion

J.M. Firmender, M. K. Gavin, and D.B. McCoach (2014)

2014 Instructional practices: engaging students in verbal communication Kindergarten and Assessments in mathematics and encouraging the use of appropriate mathematical vocabulary

J.R.O. O'Brian, Nocon and Sands 2010 Students and their teachers engaged in a collaborative dialogic (2010) inquiry process (data-driven dialogue) to co-construct meaning

K. Piatek-Jimenez (2010)

2010 The course and individual task-based interviews

Grades 1 and 2 .

L.C. Rudd, M.C. Lambert, M. Satterwhite, and A. Zaier (2008)

R. Karsenty, A. Arcavi, and N. Hadas (2007)

E. Warren (2006)

S.R. De Lozano, and M.

Cardenas (2002)

R.C. Moore (1994)

S. Pirie (1991)
2008 Observe classroom interactions using Noldus Observer XT software loaded on Hewlett-Packard iPAQ handheld computers employ the touch screen of a handheld computer to record event data

2007 Ad-hoc strategies, mental calculations, idiosyncratic ideas, everyday Secondary school Mathematical rather than mathematical language, non-symbolic explanations, visual justifications and common-sense based reasoning

2006 The written tests in small groups consisted of a common structure Elementary school Written test same over the 3-year period. Each took up to 40 minutes to complete. Word problems involving Year 5 multiplication is more complicated 2002 Explicit instruction when the discourse is analyzed or formalized.

1994 Observation of class, tutorial sessions with the students, and interviews with the professor and the students

1991 Classroom mathematical discourse discussed
Grade $5 \quad$ Assessment

Undergraduate Courses and students task

Kindergarten Classroom

interactions

students task

students

\begin{tabular}{cc}
$\begin{array}{c}\text { University } \\
\text { students }\end{array}$ & $\begin{array}{c}\text { Physics } \\
\text { courses }\end{array}$ \\
\hline $\begin{array}{c}\text { University } \\
\text { students }\end{array}$ & $\begin{array}{c}\text { Mathematics } \\
\text { courses }\end{array}$ \\
Primary & $\begin{array}{c}\text { Pupil-pupil } \\
\text { discussion }\end{array}$ \\
\hline lassroom pupils
\end{tabular}

\section{RQ6: What is the Distribution of 'What', 'Who' and 'How' Associated with Mathematical Language and Learning Approach in the Articles?}

The answers to 'what', 'who' and 'how' relating to mathematical language and learning approach are grouped into three categories which is summarized in Table 8 accordingly. First, the 'what' refers to what tool or approach applied by the scholars in their research e.g. online learning, questioning, reading, instructional practices or discussion. Second, the 'who' represents students' level ranging from pre-school children, primary students, secondary students, university students or students in certain Grade. Finally, the 'how' refers to method to evaluate students' progress or achievement e.g. test, task, assessment, course or even assignment. Detail explanations for the aforementioned three categories are as follow:

First category, the 'what' represents the approaches employed in the articles to encourage mathematical language usage among students. Out of 20 articles summarized, 3 current studies employed online learning environment (Caniglia et al., 2017; Medina Herrera et al., 2019; Walkington et al., 2019) and two studies utilized technology for data collection (Rudd et al., 2008; Van Jaarsveld, 2018). In the focus of current study, technology was not merely used by the researchers to collect data; but the students themselves applied 
technology to improve knowledge, understanding and utilization of mathematical language in classroom learning.

The remaining 16 studies conducted typical approaches to encourage students' utilization and improve mathematical language in schools. Those include traditional strategy of proving the procedures (Van Jaarsveld, 2018), connecting mathematical language with numeracy skills (Hornburg et al., 2018), using vocabulary (Schmitt et al., 2019) and transitioning from informal to formal mathematical language (Caniglia et al., 2017). It shows that both typical and technological approaches have unique roles for students in mathematical language learning.

Second, the 'who' represents students' involved in the studies. The articles show mathematical language is embedded to each student level ranging from pre-school children (Firmender et al., 2014; Hornburg et al., 2018; Purpura et al., 2016; Rudd et al., 2008; Schmitt et al., 2019), primary school children (Barwell, 2015; Firmender et al., 2014; O' Brian, Nocon, \& Sands, 2010; Pirie, 1991; Warren, 2006; Walkington et al., 2019), secondary school students (Caniglia et al., 2017; Karsenty, Arcavi, \& Hadas, 2007; McGinn; \& Booth, 2018; Serder \& Jakobsson, 2016; Walkington et al., 2019) to higher level students (De Lozano \& Cardenas, 2002; Jaafar, 2016; Medina Herrera et al., 2019; Moore, 1994; PiatekJimenez, 2010; Van Jaarsveld, 2018). The presented values include two studies involving two student levels such as Firmender et al. (2014) and Walkington et al. (2019). Whilst, six studies examined primary school children and higher-level students; only five studies investigated pre-school and secondary school students. This has shown that mathematical language emphasis was given more on primary and higher education levels. Therefore, future research pertaining to mathematical language learning should emphasize more on pre-school and secondary school students.

Third category, the 'how' represents the method examining students' mathematical language. It reveals that assessment (Firmender et al., 2014; Hornburg et al., 2018; O' Brian et al., 2010; Purpura et al., 2016; Schmitt et al., 2019; Serder \& Jakobsson, 2015) was the highest number of methods used by previous researchers to evaluate students' mathematical language, followed by task (Caniglia et al., 2017; Karsenty et al., 2007; PiatekJimenez, 2010; Schmitt et al., 2019; Van Jaarsveld, 2018), courses (De Lozano \& Cardenas, 2002; Moore, 1994; Piatek-Jimenez, 2010) and assignment (Jaafar, 2016; McGinn \& Booth, 2018; Walkington et al., 2019), discussion (Barwell, 2015; Rudd et al., 2008; Pirie, 1991) and test (Medina Herrera et al., 2019; Warren, 2006). Assessment was the most selected method in the articles. It represents the emphasis given to the importance of students' active learning especially their engagement in mathematical language learning activities while promoting students' collaboration. Based on previous studies, assessment was often applied to pre-school children; whereas task, assignment and test were frequently utilized for higher and elementary levels. Courses were popular for higher level students and discussion was mostly used for early years students.

Based on the results of the systematic review, three dimensions are the focus of previous studies in the context of learning. It involve the knowledge of the meaning of words (De Lozano \& Cardenas, 2002; Hornburg et al., 2018; McGinn \& Booth, 2018; Schmitt et al., 2019; Van Jaarsveld, 2018; Warren, 2006), the application of discourse, reading and writing of mathematical language in the classroom (Barwell, 2015; Caniglia et al., 2017; Firmender et al., 2014; Jaafar, 2016; Karsenty et al., 2007; Medina Herrera et al., 2019; Moore, 1994; O' Brian et al., 2010; Piatek-Jimenez, 2010; Pirie, 1991; Purpura et al., 2016; Rudd et al., 2008; Serder \& Jakobsson, 2016), and the ability to understand word problems (Walkington et al., 2019). The biggest focus is on the application of discourse, reading and writing of mathematical language in the classroom such as verbal communication, collaborative dialogic inquiry process, task-based interviews, and discussion. This involve the efforts to explore and use words requiring response and explanation from students.

\section{DISCUSSION AND CONCLUSION}

This systematic review examined studies related to mathematical language published in Scopus. Results, first, revealed that the related articles presented from 1991 until 2019 show an increasing number; which represents the rising interest in mathematical language learning (RQ1). Second, both Social Sciences and Mathematics areas are those who were interested the most in mathematical language studies (RQ2). Third, Purpura is the prominent scholar in mathematical language (RQ3). Fourth, United States has the most scientific works executed and published in mathematical language (RQ4). Fifth, the greatest number of article publications are Purdue University and University of Witwatersrand (RQ5). Sixth, the 'what' revealed that the biggest focus is on familiarity with pattern of discourse, reading and writing mathematics which involve students' communication. The 'who' revealed that mathematical language emphasis was given more on primary and higher education levels. The 'how' revealed that assessment was the most selected method in the articles (RQ6).

Concerning familiarity with pattern of discourse, reading and writing mathematical language, this dimension involve communication between teachers and students. Through communication, teachers and students benefits in several aspects. From teachers' perspectives, it involves verbal communication which helps teachers to explore different aspects of students' perception pertaining to specific words as well as to 
detect words that are still unclear for students. Besides, the shifts in roles of teacher and learners in learning production also occurred ( $\mathrm{O}^{\prime}$ Brian et al., 2010). In performing the role, teachers need to be concerned with factors that inhibit students' comprehension involving the unspoken and shared understandings while providing opportunity for students to communicate in group; although at the beginning of the discussion, students fail to generate any idea about the expected learning (Pirie, 1991).

From students' perspective, it is important to provide students with the opportunity to utilize words so that they can learn to speak mathematically and build their own meanings. Building meaning requires combination of several words since knowledge of words alone does not assure that students will be able to communicate. Therefore, providing students with building meaning experience through communication should be guided with questions and subsequent feedback that will enhance their knowledge of mathematical language.

In certain situation, communication involve interaction with technology. Technology is mediation tool not only essential for students' online skill development but also to enhance communication. During the last decade, instructional approach was found to be an effective strategy for mathematical language learning while exposing students to utilize digital platform; although, only few studies utilized online learning environments as mathematical language approaches. There is an increasing interest on online learning which engages students with mathematical language and transforms informal mathematical language to more formal one. Therefore, researchers or educational leaders should also place high priority on developing mathematical language among students using digital platform.

However, some challenges may occur to embed mathematical language through communication among students specifically dealing with students' misconception. Two-way communication during group collaboration between student and peer may lead to misinterpretation without proper guidance. One of major problems for the listener occurs when the shared meanings are in some way erroneous. The misuse of mathematical language emerges when student creates personal vocabularies based on incorrect previous knowledge or experience which possibly misconstrued. Therefore, speaker who shares experiences using inadequate vocabulary could be guided by using other linguistic strategies such as appropriate used of written symbolism.

With respect to utilize of PRISMA procedures, identification phase is the process of building keywords whereby understanding of the words are required. For example, in finding articles related to mathematical language in the study, the researchers listed different words but within the same category for students, informal languages and formal languages. Those three categories are: a) students, pupils and children; b) informal language, everyday language, spoken language and c) formal language, vocabulary, quantitative language and spatial language. This first phase refers to the researcher's attempt to explain the meaning of words in context of mathematical language learning.

Meanwhile, the second phase is screening, and third phase is eligibility. Both require researchers to search Scopus database to obtain relevant articles before examining and analyzing the words category used in the acquired articles. Then, the relevance of articles are evaluated before the inclusion phase. This process involves the researchers' efforts in exploring the words related to mathematical language learning.

Besides, with the guidance of PRISMA procedure, self-regulated learning in online platform becomes easier and faster for researchers. Table 8 indicates a big number of articles focus on mathematical language learning among primary school and higher education students. This fact can provide further analysis on the reason for greater emphasis given at this different level.

\section{RECOMMENDATIONS}

Current review provides significant evidence from traditional perspective on mathematical language to recent focus for various levels of students regarding study approach and data collection procedure. Considering the limitations, findings of the study offer researchers, trainee teachers or other educational practitioners' initial guidance on strategies to remedy current mathematical language shortcomings for students of all levels and prevent future mathematical difficulties. This study also gives important directions for future research to continue identifying effective mathematical language approaches that can be implemented at every student level setting.

\section{ACKNOWLEDGEMENTS}

The authors would like to convey their gratitude to Ministry of Education Malaysia for the scholarship, and School of Educational Studies, Universiti Sains Malaysia, Penang for the research support.

\section{REFERENCES}

Alkhateeb, M. A. (2019). The language used in the 8th grade mathematics textbook. EURASIA Journal of Mathematics, Science and Technology Education, 15(7), 1-13. https:/ / doi.org/10.29333/ejmste/106111

Aydin, H. (2019). The effect of multiple intelligence(S) on academic success: A systematic review and metaanalysis. Eurasia Journal of Mathematics, Science and Technology Education, 15(12). https://doi.org/ 10.29333/ejmste/109008 
Bakhtin, M. M. (1981). The dialogic imagination: Four essays. Austin, TX: University of Texas Press.

Barwell, R. (2015). Formal and informal mathematical discourses: Bakhtin and Vygotsky, dialogue and dialectic. Educational Studies in Mathematics, 92, 331345. https:/ / doi.org/10.1007/s10649-015-9641-z

Caniglia, J., Borgerding, L., \& Meadows, M. (2017). Strengthening oral language skills in mathematics for english language learners through Desmos ${ }^{\circledR}$ Technology. International Journal of Emerging Technologies in Learning, 12(5), 189-194. https:/ / doi.org/10.3991/ijet.v12i05.6947

De Lozano, S. R., \& Cardenas, M. (2002). Some learning problems concerning the use of symbolic language in physics. Science E Education, 11, 589-599.

Genç, Z., Masalimova, A. R., Platonova, R. I., Sizova, Z. M., \& Popova, O. V. (2019). Analysis of documents published in scopus database on special education learning through mobile learning: A content analysis. International Journal of Emerging Technologies in Learning, 14(22), 192-203. https://doi.org/10.3991/ijet.v14i22.11732

Falagas, M. E., Pitsouni, E. I., Malietzis, G. A., \& Pappas, G. (2008). Comparison of PubMed, Scopus, Web of Science, and Google Scholar: strengths and weaknesses. The FASEB Journal, 22(2), 338-342. https:/ / doi.org/10.1096/fj.07-94921sf

Firmender, J. M., Gavin, M. K., \& Mccoach, D. B. (2014). Examining the relationship between teachers" instructional practices and students' mathematics achievement. Journal of Advanced Academics, 25(3), 214-236. https://doi.org/10.1177/1932202X14538 032

Hornburg, B. C., Schmitt, S. A., \& Purpura, D. J. (2018). Relations between preschoolers ' mathematical language understanding and specific numeracy skills. Journal of Experimental Child Psychology, 176, 84-100. https://doi.org/10.1016/j.jecp.2018.07.005

Jaafar, R. (2016). Writing-to-learn activities to provoke deeper learning in calculus. PRIMUS, 26(1), 10511970. https://doi.org/10.1080/10511970.2015.105 3642

Karsenty, R., Arcavi, A., \& Hadas, N. (2007). Exploring informal mathematical products of low achievers at the secondary school level. Journal of Mathematical Behavior, 26, 156-177. https://doi.org/10.1016/ j.jmathb.2007.05.003

McGinn, K. N., \& Booth. J. L. (2018). Precise mathematics communication: The use of formal and informal language. Sociedad Española de Pedagogía, 70(3), 165184. https:/ / doi.org/10.13042/Bordon.2018.62138

Medina Herrera, L., Castro Perez, J., \& Juárez Ordonez, S. (2019). Developing spatial mathematical skills through 3D tools: Augmented reality, virtual environments and 3D printing. International Journal on Interactive Design and Manufacturing (IJIDeM), 13, 1385-1399. https://doi.org/10.1007/s12008-01900595-2

Moher, D., Liberati, A., Tetzlaff, J., Altman, D. G., \& the PRISMA Group. (2009). Preferred Reporting Items for Systematic Reviews and Meta-Analyses: The PRISMA Statement (Reprinted from Annals of Internal Medicine). Physical Therapy, 89(9), 873-880. https:/ / doi.org/10.1371/journal.pmed.1000097

Moore, R. C. (1994). Making the transition to formal proof*. Educational Studies in Mathematics, 27, 249266.

O' Brian, J. R. O., Nocon, H., \& Sands, D. I. (2010). The use of dialogue and tools to develop students' mathematical language and meta - cognition. Teacher Development, 14(4), 447-466. https: / / doi.org/10.1080/13664530.2010.533487

Odabasi, M., Uzunboylu, H., Popova, O. V., Kosarenko, N. N., \& Ishmuradova, I. I. (2019). Science education and mobile learning: A content analysis review of the web of science database. International Journal of Emerging Technologies in Learning, 14(22), 4-18. https:/ / doi.org/10.3991/ijet.v14i22.11744

Ozcinar, Z., Zakirova, V. G., Kurbanov, R. A., \& Belyalova, A. M. (2019). Analysis of the documents published in the web of science database on teachers' gamification method: A content analysis. International Journal of Emerging Technologies in Learning, 14(22), 82-94. https://doi.org/10.3991/ ijet.v14i22.11741

Piatek-Jimenez, K. (2010). Students' interpretations of mathematical statements involving quantification. Mathematics Education Research Journal, 22(3), 41-56.

Pirie, S. (1991). Mathematical discussion: Incoherent exchanges or shared understandings? Language and Education, 5(4), 273-286. https://doi.org/10.1080/ 09500789109541315

Purpura, D. J., Napoli, A. R., Wehrspann, E. A., \& Gold, Z. S. (2016). Causal connections between mathematical language and mathematical knowledge: A dialogic reading intervention. Journal of Research on Educational Effectiveness. https:/ / doi.org/10.1080/19345747.2016.1204639

Rudd, L. C., Lambert, M. C., Satterwhite, M., \& Zaier, A. (2008). Mathematical language in early childhood settings: What really counts? Early Childhood Education Journal, 36, 75-80. https://doi.org/ $10.1007 /$ s10643-008-0246-3

Sanger, M., \& Giddings, M. M. (2013). A simple approach to complexity theory. Journal of Social Work Education, 48(2), 369-376. https://doi.org/ 10.5175/JSWE.2012.201000025

Schmitt, S. A., Purpura, D. J., \& Elicker, J. G. (2019). Predictive links among vocabulary, mathematical language, and executive functioning in 
preschoolers. Journal of Experimental Child Psychology, 180, 55-68. https://doi.org/10.1016/ j.jecp.2018.12.005

Serder, M., \& Jakobsson, A. (2016). Language games and meaning as used in student encounters with scientific literacy test items. Science Education, 100(2), 321-343. https:/ / doi.org/10.1002/ sce.21199

Simpson, A., \& Cole, M. W. (2014). More than words: a literature review of language of mathematics research. Educational Review, 1-16. https://doi.org/10.1080/00131911.2014.971714

Van Jaarsveld, P. (2016). Making a case for exact language as an aspect of rigour in initial teacher education mathematics programmes. Perspectives in Education, 34(1), 150-166.

Van Jaarsveld, P. (2018). Juxtaposing Secondary Mathematics Procedural Routines and their Metanarratives - Exploring the Vocabulary of Student Teachers. African Journal of Research in Mathematics, Science and Technology Education, 22(2), 209-220. https:// doi.org/10.1080/18117295.2018.1480138

Voronina, M. V., Tretyakova, Z. O., Krivonozhkina, E. G., Buslaev, S. I., \& Sidorenko, G. G. (2019).
Augmented reality in teaching descriptive geometry, engineering and computer graphicssystematic review and results of the russian teachers' experience. EURASIA Journal of Mathematics, Science and Technology Education, 15(12), 1-17. https://doi.org/10.29333/ejmste/ 113503

Walkington, C., Clinton, V., \& Sparks, A. (2019). The effect of language modification of mathematics story problems on problem - solving in online homework. In Instructional Science. https:// doi.org/10.1007/s11251-019-09481-6

Warren, E. (2006). Comparative mathematical language in the elementary school: A longitudinal study. Educational Studies in Mathematics, 62, 169-189. https:// doi.org/10.1007/s10649-006-4627-5

Zack, V. (1999). Everyday and Mathematical Language in Children's Argumentation about Proof. Educational Review, 51(2), 37-41. https://doi.org/ 10.1080/00131919997579

Zinn, C. (2006). Supporting the formal verification of mathematical texts. Journal of Applied Logic, 4, 592621. https:/ / doi.org/10.1016/j.jal.2005.10.010

\section{http://www.ejmste.com}

